\title{
Study of the Legal Regime of Oil and Gas Transit in Energy Charter Treaty and Law of Iran
}

\author{
Seyedeh Koyestan Sharify ${ }^{1}$ \& Ali Mohammad Mokarrami ${ }^{2}$ \\ ${ }^{1}$ Department of Law, UAE Branch, Islamic Azad University, Dubai, UAE, Dubai, UAE \\ ${ }^{2}$ University of Judicial Sciences, Tehran, Iran \\ Correspondence: Seyedeh Koyestan Sharify, Department of Law, UAE Branch, Islamic Azad University, Dubai, \\ UAE, Dubai, UAE
}

Received: May 15, 2016 Accepted: June 6, 2016 Online Published: June 29, 2016

doi:10.5539/jpl.v9n5p194 URL: http://dx.doi.org/10.5539/jpl.v9n5p194

\begin{abstract}
The present thesis has analyzed the legal regime of oil and gas transit in energy charter treaty and law of Iran by the use of descriptive analytic method. The research findings show that the law of transportation and the transit of foreign goods through the Islamic Republic of Iran's territory passed in 1995 and its executive by law generally deals with the transit affairs although because of its general application it can be stated that it includes energy transit especially oil and gas. This law has referred to the energy transit in a limited way and therefore the lack of law in this respect is quite conspicuous. The transportation law of Iran which was ratified about 14 years ago and since it was codified for the needs of those days need to be revised in case Iran intends to join the charter because in several cases there is lack of law. But despite the legal vacuum there is no contrast between the aforementioned law and the contents of the charter treaty in terms of the oil and gas transit. In fact it can be stated that the law of transportation of Iran has no limitation in accepting the contents of the charter but only in some cases for the sake of clarification and preventing the creation of difference some new rules need to be ratified and some of the present rules need to be modified.
\end{abstract}

Keywords: Transit, oil, international energy treaty charter, the law of transportation and the transit of foreign goods through the territory of Islamic Republic of Iran

\section{Introduction}

Energy transit has always been attended as one of the significant issues in the international trade law. To do transit the presence of strong political relation and the agreement of the countries in this respect is the required condition but to fulfill it the countries need to sign a contract in which the right of transit and the related conditions and regulations are clearly determined. It is only under such a contract that the countries obtain international commitment to give transit permission. At the same time it is possible that the aforementioned contract be between two or several countries about a special project or in general.

In Iran the law of transportation and the transit of foreign goods through the Islamic Republic of Iran's territory consist of twenty six articles and four remarks which was ratified on Tuesday, $26^{\text {th }}$ of March 1995 and was confirmed by the guardian council on 27/12/1995. The aforementioned law practically constitutes the foreign transit rules of Iran. But sometimes countries officially recognize the right of transit from their territory for a country or some countries in a particular project the same as all mutual agreements that are bilaterally signed between countries. Sometimes in a multilateral international document the related countries accept this right generally and become committed to grant transit permission to the other countries the same as energy charter treaty which is about the arrangement of member countries relations about different aspects of the energy sector and part of it deals with transit. ${ }^{1}$ Special rules have been considered for the energy transit. And a system of dispute settlement has been predicted for the resolution of the differences. Before the energy charter treaty become enforceable the article 5 of the GATT was an enforceable international rule in terms of the transit based on which the non-discrimination principle was observed. Quick rise of the energy transit in recent decade caused the transit operation particularly in terms of the expenses of the service providers and the transit path becomes complicated. This problem showed that the article 5 of GATT is no longer capable of answering all transit related

\footnotetext{
${ }^{1}$ Malek Reza Malekpoor, transit of goods and its importance in the economy of the country, Darya payam, N53, 2005, p.162
} 
problems therefore there was a need of more detailed rules to guaranty transit on the basis of reasonable rules. ${ }^{2}$ The charter is founded in line with the GATT principles and emphasis on non-discrimination and freedom of transit and access to it. As a result of further follow up of the issues related to the energy transit all of the charter members with consensus concluded that charter rules in terms of the transit need reinforcement therefore, the charter conference in $7^{\text {th }}$ of December meeting made the transit group responsible to prepare charter transit protocol. ${ }^{3}$ The present study is an attempt to analyze the energy treaty charter transit rules with an emphasis on transit rules and in comparison with that. To this end, first the concept of transit, and the rules of the energy treaty charter and then the rules of Iran and charter treaty are comparatively analyzed.

\section{Oil and Gas Transit}

Transit in terminology means passage, way and path and the transit of goods means the entrance of goods from one border and the exit from another border that can be done by the use of transportation facilities of that country. ${ }^{4}$ Transit of goods may be done via land (railroad or road), air, or the coastal waters of the country. The country that provides the facilities of the transit of goods benefits itself and reaches the freight from a more apposite path to the destination.

The transit products that pass through the countries benefit from the fundamental transportation facilities such as rails, roads etc and therefore significant investments are done in this respect to increase foreign exchange earnings. On the other hand the freight would reach to the destinations faster and cheaper and less transportation expenses are imposed on the owner of the goods. This leads to cheaper distribution of the goods in the consumption market and consequently the expansion of the export of the exporting country. Iran because of its special position next to the central Asia and Caucasus countries and the bridge in between two large continents of Asia and Europe and because of its access to the open waters has a lot of significance in terms of regional relations. Special geographic relations potential and practical economic abilities, political security and stability, having long coasts along the open seas and the apposite facilities are among the factors that can have a significant role in the transit of the goods of the central Asia and the Caucasus countries.

Goods would be transited through a country when it is generally economic. The role of the transit as an issue in international law has a multiple relation with various aspects of the human life. International trade, tourism, and remote communication are among a few examples that show without the transportation through a third country which is not the destination of the freight is impossible. Transit has always been considered as a critical necessity of the energy markets. "From an investor's vantage point energy projects especially in Eastern European countries has a high political risk. Lack of the existence of a secure legal framework and the contradiction between rules and regulations makes investment over a long term if not impossible but definitely difficult." 5

From economic vantage point safe and secure transportation from the production region to the consumption region is a critical issue for many countries. Particularly the oil crisis in early 70 s has lead to the higher demand of the Western countries to guaranty more energy products because the present gas resources in Europe (such as Holland, Norway, and the North Sea) is not sufficient for the oil and gas demand. By observing the expansion of natural gas production up to 2000 most of the used gas in West Europe originates from the natural products.

But $18 \%$ of it from Russia, $12 \%$ of it from Algeria and $10 \%$ from Nigeria and Libya in addition to potential factors are provided from the serious projects. As far as the distance of oil reserves are attended Europe is highly dependent to the import of oil from Russia, Africa, Saudi Arabia and other Persian Gulf States. ${ }^{6}$ Therefore, countries in order to transfer the oil reserves depend on pipe line and other transit methods to transport fuel from the production point to the consumption point and this has lead to the development of trade development in terms of transit. Today for the producer countries and consumer countries as well as investing companies in energy sector it has become evident that oil and gas as two types of fossil fuels will remain for several coming years as the only reliable energy source for the development of economy and according to this view long term investment on constructing international pipe lines not only wastes the capital but it is very necessary.

In many cases the international trade is just possible through the transit of material and products though the

\footnotetext{
2 - Kononoplianik, Andrei, The Energy Charter Treaty, A Reader's Guide, The Main Elements of the ECT (part II), at < http:// www.encharter. org>, last visited: 2015 /02/10.p. 29

3 - Sanam Salem Haghighi ,Energy Security: The External Legal Relations of the European Union with Major Oil and Gas Supplying Countries . Oxford: Har， 2007,131

4 - Malekpur ibid,62

${ }^{5}$ Liesen, Rainer,Transit Under The 1994 Energy Charter Theraty ,17 Journal Of Energy and Natural Resource law,1999, p.55

${ }^{6}$-ibid, p56
} 
territory of a third country. Therefore, the highest relation and role of transit in terms of the transit countries can be imagined. ${ }^{7}$

Part 10 of the article 7 of the charter defines transit as follows:

A: transportation via the territory of one of the sides of the treaty either by port facilities within the territory or the loading and unloading facilities of the energy materials and products whose destination is another state to the third state territory as long as the other state or the third stare is part of the treaty.

B) Transportation of energy materials and products through the territory of a member of the treaty whose destination is the other side of the other to the destination of the territory of another member except that two sides of the treaty decision otherwise and register their decision with a common entrance. ${ }^{8}$

On the basis of the abovementioned definitions the following issues are considerable:

A: As we know on a relation based on transit principally three parties are present: the departure country, the destination country and the transit country. On the basis of the contents of part A of the article 10 only it is required that only the transit country and one of the departure or the destination countries are the member countries of the charter. But despite that it is necessary to explain that in this case to solve the dispute settlement mechanism all of the three countries need to be the member countries of the charter. Therefore, a country that is not part of the charter can not follow the procedure of dispute settlement on the basis of the contents of the charter.

B) Transit can also happen between two countries. For the oil pipe may start from country A and enter the country B and then return to country A. This happens in the pipe line that enters Moldavy from Ukraine or the Russian pipe line that passes the Ukraine territory and the pipeline that enters from Turkmenistan into Kazakhstan. ${ }^{9}$

C) It's worth mentioning that the first part of the remark 10 in the definition of the transit "transportation through the territory of has mentioned which has a different legal definition from the lands under the sovereignty of the countries in the discussion. The statement territory also includes the sea territory that the countries on the basis of the international law of the seas have the sovereignty on them. Therefore, in case a pipe line passes through the aforementioned territory the contents of this part would rule it.

D) It seems that the concluding statement of the second note of the aforementioned article has limited the concept of transit. Because, on the basis of that each of the sides of the treaty can make a decision on the basis of their transit paths, so far only Unites States of America and Canada have been in this list and both of them have signed the charter and have not signed it yet.

\section{Transit in the Law of Iran}

In the transit law of Iran the goods that enter as transit are not considered as the export-import goods and for the same reason no customs duties or tariffs etc. are imposed on them. But in terms of the customs expenses (stocking, loading and unloading) special regulations have been determined within the international customs rules. Generally the foreign transit goods after doing the customs procedure in the entrance customs need to move directly towards the exit border customs. Customs to make sure of the exit of the goods is authorized to transport the transit goods at the expense of the owner of the goods by the vehicle it chooses even the state vehicle. Customs can send agent at the expense of the owner of the goods with the goods. To make sure that the goods leave the country the customs are forced to receive cash deposit guaranty or credible bond. The amount of the deposit or the bond differs on the basis of the type of the goods and the condition of its entrance. ${ }^{10}$

Trade freights are goods that have credible transportation documents, receipts, package list etc.

Such freights need to enter through the authorized borders into the country and in the first customs house eligible to do customs operations, the goods owner or the carrier company (on proxy of the owner of the goods) arrange the transit statement in two copies and the entering freight along with the carrier tool (in case the carrier vehicle possess valid international license). ${ }^{11}$ Declare as foreign transit to the customs and provided the required

\footnotetext{
7 - Liesen, Rainer,Op.cit

${ }^{8}$ Clark, Bryan. "Transit and the Energy Charter Treaty: Rhetoric and Reality”. Web Journal of Current Issues, 1998,p.134

9 - ibid.p.6

10 - Article one of the transportation law and the transit of foreign goods through the territory of Islamic Republic of Iran

${ }^{11}$ Part $\mathrm{C}$ of the article of executive by law of transportation law of the transit of foreign goods through the territory of Islamic Republic of Iran ratified in 1998
} 
documents along with the statement to the customs to be controlled. The appended documents to the customs declaration consist of purchase documents of the goods, list of the package (in case of variety of goods), bill of loading, the certification of the departure and if required the license of Iran's customs or the state committee (depending on that the goods are authorized, conditional, unauthorized, or forbidden to enter) on the basis of the agreement with foreign goods transit.

The owner of the transit goods or his agent, at the time of arranging the transit declaration needs to record the complete and accurate features of the transit goods. These features include number, type of packaging, correct value and tariffs of the article. In this case the foreign transit goods after surrendering the declaration and doing the primary procedures are evaluated and assessed by the customs officials and in case of complete congruity between declared goods and the transit declaration the transportation vehicle and the packages are sealed so that they can not be manipulated.

In case the result of assessing is not in accord with the presented declaration the assessment department of the customs arranges a complement declaration and the complementary assessment procedure to issue customs document with precise features of the transit goods.

According to the article 268 of the executive by law of the customs and its revision in case the goods declaration is not accurate and the discovery of the contradiction requires financial damage of the state or to detect contradictory cases while assessing that are among smuggling items depending on the case apposite fine and penalty of the wrongdoer will be imposed.

After doing the assessment operation the issuing of the transit license depends on placing the cash security in escrow. The rate of the cash security of the authorized goods is an amount equal to all customs, commercial benefit, and the tariffs on the import of that article. For conditional goods the maximum amount of the cash security is five times (value of the article + customs + commercial profit + customs tariffs) in addition to the value of the goods. ${ }^{12}$ In terms of the forbidden goods the maximum amount of the cash security is five times (value of the article + customs + commercial profit + customs tariffs) in addition to the several times more than the value of the goods by the recognition of the customs in a way assures the customs of the exit of the goods from the country. According to notes 6,4,2,7 of the article 29 of the customs affairs no exit, delay or removing the goods (article reduction) non-declared article along with transit goods (additional article) and not transiting the goods within the allotted time, include the customs smuggling. One committing such an act must pay a fine of smuggling and legal punishments. At the entrance of the transit good into the country the customs determine the cash security at a rate to fulfill the costs and expenses of the state in case of not exiting the country the fines and the earnings of the state get paid from the cash security. It is evident that the provision of the state fines and earnings do not prevent the other punishments and legal penalties. (The penalty of the smuggling at the present time is five times of the value of the article and the confiscation of the article.) The customs of Iran to facilitate the procedures and create facilities can accept insurance certification from the transit applicant instead of the cash security. In this case the owner of the goods or their agent should append the insurance certification onto the declaration. This certification need to have the signature of the insurance company and the insured party and the shipping association and the related services. Otherwise the insurance certificate has no credit. In terms of the goods transported by the selection of customs or via state post or the state transportation company customs can accept a written credible security instead of part of the cash security. ${ }^{13}$

In case the transit transportation vehicles possess international passage license (diptic, Tryptic, and Karne two passage) these vehicle by the credit of the aforesaid notebooks commute but all of them observe the foreign transit regulations.

Foreign transit goods do not require receiving license according to the rules and regulations of the state organizations but for the transit of through the country the approval of the customs goods transit supervisor and if the goods are state forbidden ones there should be a permission of the customs of Iran supervision and legal issues deputy should be provided. For forbidden goods the license for both cases should be provided from the state committee.

\section{Transit in energy charter treaty}

After the collapse of the USSR there were several new opportunities for the Western countries to make investments. This investment was very significant in terms of oil and gas resources. The resources that were untouched up to that time or were less touched. And also the Western consumer countries to have access to the

\footnotetext{
12 - Article 12 of the executive by law

${ }^{13}$ - Remark 3 of the article 3 of the by law
} 
Eastern Europe energy resources and their imports were highly in need of safe routes to transit goods.

Since the economic and political interests of the transit were critical for some of the consumer countries therefore the talks about the need for a transparent, legal and lawful framework to provide non-discriminative access of all countries to energy products started. Otherwise the producing countries or consumer countries would be dependent on the decisions of the transit countries and only on the basis of mutual agreements or on the basis of general international law would be able to resolve their problems.

Contents of the energy charter are created to settle such problems and one of the goals is to eliminate $r$ at least reduce the dangers of transportation caused by political and economic disputes between the disputing countries. In this respect the article 7 of the charter has predicted special rules which consist of 10 parts and several elements. This article that only deals with energy has special rules that would be discussed in this part and the following parts. ${ }^{14}$

Such as the transit freedom principle, no discrimination principle, commitments such as renewal and development of the internal and regional transportation and border connections, no energy transit current cut, no creation of delaying obstacles, co-operation in terms of reducing the impact of energy distribution, and support in terms of reducing the impacts of energy distribution cut and support in terms of renewing facilities and the settlement of disputes caused by transit.

In this part in addition to the definitions of the transit in the charter notes 1-4-5 and 9 which are about freedom and access to transit will be discussed.

\subsection{Freedom of Transit ${ }^{15}$}

As explained earlier energy charter treaty in the transit part seeks special goals and one of them is the freedom of transit. As we know transit as a critical necessity in the international trade is highly significant for the countries enclosed by land. In other words, although all other countries need transit for the development of their international trade but this necessity is far more for the countries enclosed by land. For the same reason many of the treaties in the past in the transit part have referred to the sea transportation or transit.

The subject of freedom of transit apparently seems to be a new subject but its background goes back to $17^{\text {th }}$ century. Grotos in his theory has considered the general right of transit within the territory of other countries for the benefit of international communities. In this respect Prof. Kaflishen after a comprehensive analysis of the enclosed states transit issue states that: "at international level law the rights of the enclosed countries in transit and right of access to sea ports are indefinite and unstable"16. Gorgsel the well-known lawyer by considering it as a profit-right which limits the right on territory in this respect believes that passage right in general law provides the enclosed countries to pass through the countries that separate them from the sea without a need for international agreement or treaty"17 therefore, it can be observed that freedom of transit as an international custom is approved then international treaties system is also influenced by it.

One of the conventions related to the transit is the Barcelona convention. This convention is about the rail and sea transportation. In article 2, "nondiscrimination principle in terms of nationality of the persons, flags of the ships, departure entrance exit or on the basis of any situation and condition related to the owners of the goods are negated." 18 And also in the third article states that: "receiving any type of customs from the commercial goods is forbidden". Also in New York convention in force major cases the member countries should take required measures for preventing limitations of passage and transit. In case of the occurrence of the more critical delays of special pauses according to the note 2 of the article 7 of the convention the mutual co-operation of the corresponding states to eliminate it quickly". ${ }^{19}$

General tariffs treaty and trade is also in line with the support of the freedom of transit principle has ratified interesting rules. The article 5 of the aforementioned treaty states that: freedom of transit should exist within the territory of each of the sides of the agreement. There should be no differentiation between ships on the basis of the flags they have, departure point, path of the movement, the path of the entrance, exit, and the destination or

\footnotetext{
${ }^{14}$ Tarom sari, Masud, The settlement of the disputes in energy charter treaty and its comparison with obligatory rules and regulations of Iran, energy international studies institute, sprin and summer of 2005,p.41

${ }^{15}$ Freedom of transit

${ }^{16}$ Joneidi Laya comparative analysis of international trade arbitration Tehran: Tehran University, 1999, P.141

17 ibid, p. 156

18 ibid,162

19 -ibid, p171
} 
other related conditions related to the ownership of the goods or the ships or other transit paths."

also part and 6 of the article 5 states that: "any transportation and executive expenses should be ratified under rational and non-discriminative tax". ${ }^{20}$ The contents of the article 5 of GATT more than ever emphasizes on the principle of no discrimination, additionally the tax expenses need to be posed in a non-discriminative basis.

Therefore it seems that the first legal framework in terms of the transit can be the article 5 of the aforementioned treaty. But since this article has not been able to solve all issues and problems related to the transit issue therefore, there is need of more transparent principles and regulations in terms of securing freedom of transit.

After the formation of energy charter treaty the transit issue was expansively supported. But before that it should be discussed that the first principle that contradicts the principle of freedom of transit is the principle of sovereignty of the states. Since this principle has been a known international law and it is considered as the state-country guaranty therefore it seems that the principle of the freedom of transit can not be interpreted in its absolute sense or used. For the same reason the charter tries to create an international balance between the governmental interests of the states and their need to the guaranty and stability of the transit.

The principle of the freedom of transit explicitly in part 1 of the article 7 of the charter has been mentioned: "each side of the agreement would take the required measures to facilitate the transit of energy materials and products on the basis of the principle of the freedom of transit without discrimination in terms of departure, destination or the ownership of these materials or the energy products or discrimination in terms of pricing on the basis of such discrimination and without imposing any type of limitation delay or irrational expenses"

By scrutinizing the aforesaid issues it can be seen that the charter no only has accepted the principle of the freedom of transit and lack of discrimination as a principle but has urged the countries to take required measures in this respect. Despite that different views have been put forward in this respect. Rugen Camp has stated that: "the interpretation of part 1 of the article 7 presents a weaker concept of what has been expressed in GATT article. Because the necessary measures to facilitate transit has less intensity compared to ensuring freedom. ${ }^{21}$ In other words the mere obligation of the countries to take necessary steps because of its generality does not mean that they ensure the freedom of transit.

It is axiomatic that every legal establishment shows its practical capacity in practice. In other words we can talk about the interpretation of the principle of freedom of transit when it is challenged. On the other hand the existence of such a principle without considering executive guarantee for it would exist at the level of a theory and may lose its practical and functional concept.

\subsection{Access to Transit}

It is very evident that the amount of energy is limited in the world. On the other hand the expansion of international energy trade level has lead to the dependence of countries to each other. Therefore countries are always concerned about securing their energy. One of the issues related to the energy which is always discussed is the access to the transit or in other words the guaranty of transit distribution. The concept of energy security as an international requirement was first put forward in 1970 as a result of the disruption in the oil products. Over 1990 most of the Western countries and most of the developed countries had forgotten energy security but in the early twenty first century we observed a new concern which focuses over the energy market and energy products guarantee and international security. This concern not only includes the producer and consumer countries but also the investing companies. As we know transit has a close relation with transit and investment. In other words the issues related to the transit such as creating the infra structures required for transit, constructing various types of pipes, renewing the facilities and the energy transport facilities etc. and all of them require investment. In fact different factors are engaged so that energy is timely provided for the consumer and the transit is optimally done. Because energy has no value except at the time of need be available especially for those products that are transferred by a stable transport network such as gas and electricity ${ }^{22}$

Access to transit originates from the principle of freedom of transit. Charter has considered commitments for the access of transit for the countries. Commitments such as renewing and developing the function of internal and regional transportation and border connections, not cutting the energy transit, not creating obstacles causing delay, co-operation in reducing the impact of energy cut, co-operation and support to renew facilities and equipments of energy transfer, installing or establishing new capacities of transportation. In addition to part

\footnotetext{
20 - Clark, Bryan, Op.cit,p.3

${ }^{21}$ Martha M. Roggenkamp ,ENERGY \& LAW , University of Groningen, the Netherlands, editor in chief,2001,p.114

${ }^{22}$ - ibid: 6
} 
1which deals with general principles such as the principle of freedom of transit parts 4 and 5 of the article 7 is in this respect.

Part 4 states that: "when it is not possible to transit energy materials and products by the use of energy transfer facilities on the basis of trade conditions the sides of the agreement would not put obstacles ahead of the new capacities except that in the applicable law in line with part 1 another way is stated."

From the contents of the abovementioned articles the following issues can be deduced:

1) The purpose of conformity with part 1 is the same as the principle of freedom of transit and non discrimination

2) It can be stated that the abovementioned part is an exception to the transit on the basis of article 7

3) The contents of this article if leads to the creation of new or more facilities seems to be useful and in fact a new form of transit at international level will be delivered.

4) This part by referring to the statement "applicable law" has provided countries with a broader range of action in other words this article is the reflection of the influence of political interests of the states. This issue is one of the instances of the charter in supporting the sovereignty of the states.

5) By considering the security of the transiting country it seems that the charter has tendency towards the support of the state sovereignty although such exceptions have become limited in practice but these exceptions would not be something more than facial support of the state interests. ${ }^{23}$

It seems that the contents of the next parts $(5,6)$ are attempts to complete part 4 of the article 7 . Article 5 states that: "the responsible side from where the energy materials and products are transited would not be obliged to observe the following items:

A) Construction permission by changing the energy transfer facilities;

B) Permission for new or additional transit via energy transfer facilities to prove other related sides of the treaty that it is possible to endanger the security and efficiency of energy system such as the distribution security; the sides of the treaty guarantee the present energy materials and products current to, from or between the territories of the committed sides by observing the parts 6 and 7."

The recent part of the aforementioned part is one of the most important elements that can be executed because explicitly urges the countries to observe the energy current security guarantee. Therefore in coordination of this part with the contents of part 4 it can be observed that the decision making of the states have become practically limited and as a results states need to refrain from risky actions. In other words, although the charter encourages the establishment of new capacities but if these actions endanger the security of delivery of energy the states should refrain from it. Therefore, any action taken by the states is dependent on guarantying the committing side of not doing endangering actions.

Additionally part 9 of the aforementioned article state that: "this article would not be interpreted in away that any side of the treaty that lacks a special type of facilities of energy transfer used for the transit is obliged to take any action in terms of the energy transfer facilities. Anyway the committed side is responsible to observe part 4". It seems that contents of the article 9 are intended to completed part 4 . On the other hand it can be stated that the contents of article 7 are not acceptable and a bit complicated.

In order to rationalize the contents of this part Fatrus suggests that: "the relation between part 9 and 4 of the

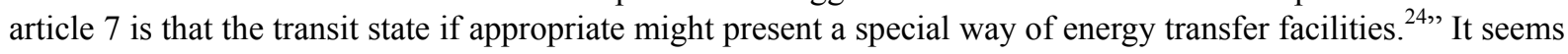
that the contents of the aforementioned article largely intend to create a number of international commitments to support transit current more than anytime. Such as the explicit reference to no creation of obstacle ahead of the new capacity to transit is an unprecedented event. Among the other items that show the supportive aspect of the article 7 are the contents of part 3 that urges the countries to take a unilateral method in internal regulations in accord with transit. Part 3 of the article 7 states that: "each of the contractor sides undertakes that the rules about energy materials and products and the use of energy transit facilities in terms of energy materials and products follow the same method that employs for the materials and products whose departure and destination are within its territory unless an available international agreement orders differently."

In accord with the support of freedom and access to the transit the charter has considered other responsibilities for the contractors. According to the part 2 of the article 7 these responsibilities are as follows: "the contracting

\footnotetext{
${ }^{23}$ Bryan, Op.cit,p.5

24 -ibid, p.5
} 
sides would encourage the related units for the cooperation in the following fields:

A: Renewing the energy transit facilities necessary for the transit of energy materials and products

B: Development and establishment of energy transit facilities at the service of more than one territory of the contractor side

C: Taking actions to reduce the impact of cutting the supply of energy materials and products

D: Facilitating the connection of energy transportation to each other

Charter by the reference to the aforementioned items tries to create an international cooperation to have free general access to the transit. It seems that countries in reaching their goals have to ratify new laws or sign bilateral or multilateral contracts.

\subsection{Non-interference in Transit}

One of the goals of the charter in terms of the transit is the principle of non-interference of states in transit. The contents of the note 6 of the article 7 states that in case of the occurrence of any dispute among the member countries of charter in terms of the transit the country through which the energy materials and products pass should not directly cut the transit of oil and gas or reduce it or ask the subsidiary foundations to do that as long as the dispute among them is not resolved on the basis of part 7 of this article unless the cut of transit in the energy transfer has been predicted or on the basis of the verdict of the reconciler that the sides have referred to such a decision is made. ${ }^{25}$

On the basis of the abovementioned note when the transit passes through a country the aforesaid country is committed to prevent interference in the transit process. In this case it makes no difference whether the government is responsible for the transit or the under control companies and foundations. Therefore in cases where a private non-state company is responsible for the transit of the energy and intends to make interference in the process the country whose territory is used for the transit is responsible to prevent the cut or reduction of energy transit. This issue is very critical that makes countries responsible to take preventive measures to forbid interference in transit. Also it is among the factors that makes states responsible in the face of the private individuals' behaviors. ${ }^{26}$

Despite that it's worth mentioning that the responsibility of the government is when the possibility of cut or reduction of energy transit is not predicted but in case there is such a possibility for the contractor doing that is not a violation of the charter and does not create international responsibility for the country. The point that needs to be considered in this respect is the transit process cut or interference from the departure country. In other words when the transit country causes interference in transit includes this article but when the departure country and the energy sender because of a dispute stops the energy current it is impossible to make it responsible on the basis of this article. Therefore it can be seen that the contents of the charter are contradictory in this respect and

can not completely guarantee the principle of freedom of transit. Because the transit issue is not only limited to the transit country but it requires the cooperation of departure and destination countries for the complete fulfillment of the transit.

One of the other weaknesses of the aforementioned article is that it considers the non-interference in transit merely limited to the disputes caused by transit and it is inattentive to other differences that may lead to cut or reduction of energy current. As we know the interference in transit by the transit country might have various reasons and one of them is the differences in terms of the transit. One of these differences might be the political differences or the differences over the rate of the tariffs. Therefore, it seems that the transit country in cases apart from transit is authorized to create interference in transit process.

It's worth mentioning that the contents of the chapter have predicted a case that in it the interference in transit is authorized in a subsidiary way. According to the part 6 of the article 7 if transit cut or its reduction is predicted in the contract or the ruling agreement on transit then the countries can act according to the contents of the agreement. In fact most of the transit contracts have special condition on the basis o which in special conditions the transit current cut would be authorized. The direct result of acting on the basis of these contracts would be

\footnotetext{
25 - Seifi Seyyed Jalal evolutions and issue and prospect of international arbitration lawyers journal hub center, new round N.3 2001 , p76

${ }^{26}$ - Liesen, Rainer, Op.cit,p.3
} 
the interference in transit and the violation of freedom principle. ${ }^{27}$

The other issue is that the only legal framework of transit is determined in it and other points that are required to be mentioned in a transit contract need to be mentioned are not mentioned in this remark for example, issues such as the ownership of the infrastructures of oil and gas such as the pipe lines, transference paths, the ruling regime on the transit contract, construction and provision of required technical authorizations in this respect, safety and preserving the environment and the financial provision of the construction of pipe line is not mentioned in this note. ${ }^{28}$

On the basis of the aforementioned issues it can be seen that the contents of the article 7 have not been able to support the principle of non-interference. It seems that the attempts of this article have been to reduce the arbitrary behaviors of the countries in this respect and since it includes the various interests of the countries the recorded supports of the states in this respect are not comprehensive.

\section{Comparative Analysis of Transit Rules in the Law of Iran}

From analyzing the contents and commitments of the charter in terms of the transit and the suggested protocol of energy materials and products and comparing them with the law of transportation of foreign goods through the territory of Islamic Republic of Iran the following results are obtained:

Transportation law of Iran has a general aspect and it is merely about goods that are transited through Iran and because of its application it can be state that it includes the energy transit and in particular oil and gas. Despite that the transportation law of Iran is very limited in terms of the issues related to the energy transit and does not cover all issues related to the energy sector particularly transit.

By comparing the aforementioned law and the contents of the article 7 of the charter it seems that since the contents of this charter and the appended protocol is particularly about energy transit therefore it was necessary that in the related field a number of issue be taken into consideration and predict a number of commitments and subjects.

The transportation law of Iran because of its ratification time which was about 14 years ago and that it has been passed on the basis of the needs of that period they need to be analyzed and revised in case Iran intends to join the charter because in many cases as mentioned earlier there are legal vacancies. But despite the legal vacuum there is no contrast between the aforementioned law and the contents of article 7 of the charter and the appended protocol it can be concluded that the law of transportation of Iran has no limitation in accepting the contents of the charter but only in some cases for the sake of clarification and preventing the creation of difference some new rules need to be ratified and some of the present rules need to be modified. In terms of the appended protocol Iran can also make use of the suggested condition of Russia in terms of the first avoidance for long-term contracts and the short term agreements. Despite that if Iran does not reach a clear result in terms of its commitment because of the appended protocol can refrain from joining the protocol. Because it has a voluntary feature and therefore lack of agreement on the contents of the protocol should not prevent Iran from joining the charter. $^{29}$

The contents of the protocol compared to the contents of charter have more transparency and as can be observed in many cases in the law of Iran in terms of the conformity between the contents of the protocol there is no special order. Therefore, the ratification of a number of special rules that are clear and transparent is under the attention. Besides that it is suggested that in case the decision of Iran in joining the treaty is definite the Islamic parliament ratify special rules in this respect.

As we know the chapter of dispute resolution is one of the most significant parts of any agreement. In other words one of the weaknesses of an international treaty is to predict the necessary procedures to settle the disputes. The contents of the charter are significant in the sense that charter in addition to dealing with various subjects in the field of energy sector in terms of all mentioned issues has considered a special order to settle the differences. In terms of the transit the contents of article 7 has predicted a number of cases for the settlement of differences. Besides that charter has predicted a general system for the settlement of differences that is the contents of article 27. Therefore, one of the issues that should be attended while joining the charter is the settlement of the disputes. It seems that the efficiency of every international treaty to a large extent depend on the efficiency of system of

\footnotetext{
${ }^{27}$ Hashemiyan Masud, summary of the results of work group studies ECT and the political suggestions, interenational energy studies institute, Spring, 2004, p36

${ }^{28}$ Clark, Bryan, Op.cit ,p. 8

${ }^{2929}$ - The contents of the protocol in comparison with the contents of the charter have more transparency and as can be observed in many cases of the law of Iran in terms of the coordination of the protocol contents there is no special order.
} 
dispute settlement.

The legal system of Iran to settle the differences has predicted a number of solutions. As we know in every legal system two ways of judicial and arbitration have been considered to settle the problems. These two ways have differences with each other. Charter in addition to the selection of a special method concerning the registered subjects generally has preferred the arbitration system of dispute settlement. ${ }^{30}$

Arbitration method in comparison with the judicial method has the following advantages:

A: The mutual consent and agreement on the reference of the dispute to the arbitration has a critical role but in judicial verification the consent of the sides is not the required condition. In other words the principle of the freedom of will is the determining factor in arbitration while there is no such characteristic present in judicial prosecution.

B: The verdicts issued by the arbitration are obligatory for the sides of the case. This is one of the unique features of the arbitration. Because arbitration compared to other peaceful settlement of the differences such as mediation, reconciliation, or expertise has more executive guarantee. This means that arbitration verdict the same as the issued verdict has the executive capability and in a way finalizes the action. ${ }^{31}$

C: One of the other advantages mentioned by the law for the arbitration is that the complaint against the verdict of arbitration does not stop it. In this respect the article 493 of the civil prosecution bay law states that: "complaint against the verdict issued by the arbitration can not stop its administration except that the reasons of the complaint are strong. In this case the tribunal orders for the stop of the administration of the order until the end of the verification of the complaints and issuing the final order and if required the apposite provision will be demanded from the complaining party. ${ }^{32}$

Today in international affairs we are witnessing the popularity of arbitration in terms of the trade dispute settlement. All of the aforementioned advantages have usage in terms of the settlement of international disputes.

Besides that the arbitration method of resolving the differences compared to judicial method is faster. In international issues because of the engagement of the various countries on the disputed issue and as consequence the presentation of various rules in terms of the settlement of them it seems impossible for the internal judicial judges to have familiarity and expertise therefore the inclination for the settlement of dispute by the arbitration where the sides on the basis of the type of the dispute select the intended arbiter and the related law has become more popular. Therefore, it can be observed that in arbitration the problems related to the contradiction of rules are less visible and interfering verification regulations are not present. All of these advantages have lead to the inclination of states as well as investors to the system of settling disputes on the basis of arbitration. Therefore, a country that intends to have an active role in the international trade and become successful in increasing foreign investment need to move at the same pace with international evolutions.

In the legal system of Iran the civil law verification regulation ratified in 2000 has focused its $8^{\text {th }}$ part to the subject of arbitration. Accordingly the article 454 of the aforementioned law states that: "all of those who have the eligibility to take an action can refer their case with mutual consent either their dispute is taken to the court or not and at any stage of verification." In addition to the aforementioned law Iran's international trade arbitration law passed in 1997 is obligatory in terms of the international issues. It's worth mentioning that the rules of civil law verification regulation ratified in 1999 despite being passed later than the Iran's international trade arbitration law passed in 1997 it does not annul the previous law because the late law is special and has its own particular jurisprudence. ${ }^{33}$

Iran's international trade arbitration law was ratified as an adaptation of UNCITRAL arbitration model law. This law which consists of 9 parts and 36 articles has the following features: ${ }^{34}$

A: In this law international trade arbitration law is emphasized (note 2 of the article 2 of the aforementioned law) according to which all those having the eligibility can refer their international trade disputes ether referred to the tribunals or not and at any stage of verification by the consent according to the rules refer the case to the arbitration.

\footnotetext{
30 - Mirzaee, Ali, arbitration rules from comparative perspective, Tehran, Jungle publication, 2009, P.81

31 - Madani, Seyyed Jalaledin, civil prosecution by law, Tehran, Paydar, 2003, seventh edition, first publication, pp.33-360

32 - Miri Amin Pasha international trade arbitration agreement arrangement, M.A. thesis Tehran University, 2002,P.62

33 - Muhammad zade Asl, Heidar arbitration in the law of Iran Gognus publications first edition, 2000,p89

34 - Shiravi, Abdolhosein, Study of the UNCITRAL law in terms of reconciliation in international trade, legal thoughts journal, fourth year, $10^{\text {th }}$ edition, 2006, p.121
} 
B: The validity of the arbitration agreements in terms of its form has been identified. ${ }^{35}$

C: Significant independence in terms of the form of the verification regulations for the sides and the arbiter has been approved. Note 1 of the article 27 in this respect states that "arbiter on the basis of legal rules that the sides have selected in terms of the identity of the difference will make decision. Determining legal law or system of a particular country in any way will be interpreted as identity rules of that country. The rules of dispute settlement would not include this verdict unless the sides have decided otherwise.

D: Arbitration under the supervision of arbitration organizations has been explicitly accepted. (Articles 7 and 19 and notes 2 of article 6 of the aforementioned law) note 2 of the article 6 states that: "in organizational arbitrations doing the recorded responsibilities at... is upon the arbitration organization."

E: The unbiased quality of the arbitrators regardless of their selection type has been emphasized. (Article 12 of the aforementioned law) In this law the arbiter can be questioned only when there is evidence against being independent and unbiased given the current condition and situation.

F: The arbiters have the required authorities to determine the ruling law. (Part 2 of the article 27 of the aforementioned law) in other words when the sides in terms of the determination of the ruling law have not agreed the arbiter can on the basis of the law that on the basis of the resolution of contradiction of rules verify the dispute.

G: The finality of the arbiter's verdict of the identification and execution of it is emphasized. (Articles 33 and 35 of the aforementioned law) on the basis of this law the arbiter's verdicts that are issued on the basis of rules are obligatory unless the cases that the law refer to them.

Therefore, it can be seen that within the legal system of Iran the only factors that can be mentioned in accord with the international rules are the abovementioned issues. Unfortunately concerning the issues related to the transit the only executive law is the law of foreign goods transportation and passage through the territory of Islamic Republic of Iran which has not attended the issues related to the settlement of the disputes. Therefore, the special items recorded in the article 7 of the charter for the settlement of the disputes caused by transit need to be analyzed by the general present rules in the legal system of Iran. But in terms of the general system of settlement of disputes of the charter mentioned in articles 26 and 27 they can be compared with the aforementioned issues.

\subsection{Settlement of the Disputes by Reconciliation}

In the charter different methods and mechanisms have been attended by considering the subject of difference that by giving the substitute methods to settle the earlier disputes before referring to the international tribunals has created more confidence for the investors and the traders and as a result leads to the rise of investment and the trade current among the members. As we know in terms of the transit the differences on transit should be resolved in a friendly way and through reconciliation or through the arbitration method.

In terms of the aforementioned method in part 7 of the article 7 of the charter there is no special rules in the law of Iran. The only case where there is a reference of negotiation is the law of encouraging and supporting the foreign investment ratified in 2001/12/19. Article 19 of this law states that "the differences between the state and the foreign investors in terms of the investments of the subject in question if not settled by negotiation then it will be verified in the internal tribunals unless in a mutual investment agreement with the government there has been an agreement on a different type of resolving the differences". Therefore it can be observed that the negotiation method as one of the replacing methods are approved in the legal system of Iran but this does not mean that it can be implemented to resolve the disputes caused by the transit. Although negotiation is considered as one of the non-judicial methods but negotiation is different in meaning from the reconciliation and can not be used instead of it.

Over the last twenty years the need for ratifying law towards the development and encouragement of dispute settlement through compromise and mediation has been considered by many countries. In 1998 the preparation of unified rules in terms of international trade compromise became the operational guideline of ANCITRAL and accordingly in 2002 international trade compromise sample was ratified by ANCITRAL ${ }^{36}$

\footnotetext{
${ }^{35}$ - Article 8 of the aforementioned law states in this respect that: "the court where the case of arbitration agreement has been referred to should in demand of the one of the sides to the need of the fist session of the court refer the case to the arbitration unless they find out that the arbitration agreement is canceled and invalid and can not be executed."

${ }^{36}$ - Shiravi, ibid, p1
} 
It's worth mentioning that this law is merely approved under the title of "UNCITRAL reconciliation rules" ${ }^{37}$ by the United Nations General Assembly and has not been ratified as a law. Therefore the reference of the states to this law at the time of disputes depends on their agreements. Since the aforementioned law is in relation with the international reconciliation. Since the aforementioned law is about the international reconciliation and the significance of the use of supplanting methods of dispute settlement it seems that the government of the Islamic Republic of Iran be able to make use of this law. Besides that this law has a special attention to the principle of freedom of will and the necessity of the contracts and for the same reason today the states and several centers intend to arrange reconciliation rules or the reference to the sample law.

\subsection{The Settlement of Disputes by Arbitration}

In the opinion of an international merchant, arbitration has distinctive advantages. The sides of an international contract can assign the resolution of their action to the judgment of their selected judges. Since the sides live in popular countries which have founded their rules on the basis of legal concepts that have various legal cultural and traditional backgrounds. They may not be interested in attending at national courts. Charter also considers referring to the international arbitration authorities as one of the ways of resolving differences. The first international trade arbitration law in Iran was passed in 1997 by the judiciary power.

Before ratifying this law the international trade arbitration was adapted on the basis of the general arbitration rules reflected in the civil law regulations. ${ }^{38}$ The international trade arbitration law tries to limit the interference of the courts of Iran in the arbitration verdicts and reinforce the role of the arbitration in terms of international trade actions. ${ }^{39}$

The aforementioned law has advantages such as organizational arbitration acceptance that today can answer the needs of dispute settlement through arbitration. But unfortunately the aforementioned law in case of the reference of the state authorities and international are in contradiction with principle 139 of the constitution. The principle 139 of the constitution states that the reconciliation of the actions about public properties or state or the reference of them to the arbitration in every case depends on the ratification by the committee of the ministers and should notify the parliament. In cases where the action side is foreigner and in important internal cases should be ratified by the parliament. The important cases are determined by the law." Therefore in international cases the reference of the judgment needs to be ratified by the parliament. Also in cases about the state properties the ratification of the council of ministers is required. The reason behind it is that the legislator has had a special attention to the national sovereignty and mostly emphasizes on the verification of the cases in Iranian courts.

It's worth mentioning that there is no reference concerning the requirement of ratification by the council of ministers or the parliament at the time of concluding the contract or at the occurrence of the differences and disputes in the rules. It seems that the permission should be obtained at the time of concluding the contract. Although apparently the contents of the principle 139 of the constitution are about the arbitration issue and until there is no difference the action about the public property has not happened but reference to this interpretation leave the path for the Iranian side to avoid international rules by referring to them. For example the verdict of the case number 4381 of the international commerce chamber refers to the following as the reasons to reject the reference to principle 139 by the Iranian side of the case: "the presented documents in the present case show that the defendant as a state company on the basis of the principle 139 of the constitution can not enter the arbitration agreement. But it should be considered that the deficit on the agreement has not been notified to the defendant at the time of arranging the case. The background and procedure of the arbitration because of its contradiction with the international public order that a state foundation enter the arbitration process at the time of transaction with a foreign side and provide the confidence but by the start of the procedure or the administration of the verdict refer to the invalidity of its reference."

Therefore it can be observed that the principle 139 is in contrast with any type of arbitration and the way of settling the disputes of the state and public property affairs without the ratification of the parliament. This principle causes lack of confidence of the foreign investors and states with Iranian side. Because the foreign does not like to verify the differences with Iranian side in internal courts or that the international arbitration which is the popular way of resolving disputes and differences rely on the ratification of the internal officials.

\footnotetext{
${ }^{37}$ UNCITRAL reconciliation rules

38 - Articles 623-680

39 - Shiravi, Abdolhossein, Arbitration contract arrangement on the basis of the international trade arbitration law of Iran Qom supreme education complex journal first year N.3 2008, pp65-66

40 - Seifi ibib,p114
} 
But despite that it seems that recently there has been an inclination of settling disputes through the arbitration by the legal system of Iran. This fact can be seen in the law of encouraging and supporting the investment of ECO member countries and the corrective protocol ratified in $2008^{41}$ and the law of air transportation between Iran and Philipin ratified in 2009/1/26 article 9 and 10 of the ECO agreement in terms of the settlement of the differences between contractors and also the differences between one contractor and the investors of the other side have considered the reference to the arbitration as the way of settlement of the differences. Note 2 of the article 9 of the aforementioned law in this respect states that: "2-in case the contractor side where there has been investment and the investor (investors) can not within six months from the announcement of the argument from one side to the other side come to agreement the dispute can be referred by the request of the investor to: A-valid court within the territory of the side where there has been investment or B- a case arbitration tribunal consisting of three members in the following order:

The disputing side that intends to refer the case to the arbitration selects an arbiter by sending a written note to the other side. The other side should in sixty days time from the day of receiving the aforesaid note select an arbiter and the assigned arbiters need to determine the head arbiter in sixty days from the last assignment date. In case any of the sides can not select the corresponding arbiter within the time or they do not reach an agreement over the head arbiter each of the sides can ask the head of the international trade chamber arbitration tribunal depending on the case select an arbiter or head arbiter for the abstaining side" also the article 10 of the aforementioned law in terms of the settlement of the dispute between the contractor sides states that." In case the dispute is not concluded over six days from the start by the settlement counseling each of the contractor sides can by sending notes to the other side can refer the dispute to a committee of three arbiters two select by the sides and the head arbiter. In case of the reference of the case to arbitration each of the sides of the dispute would select an arbiter within sixty days from the date of receiving the announcement an arbiter would be selected and the selected arbiters of the contractor sides within sixty days from the date of selecting the head arbiter will be determined. In case any one of the sides of the contract does not select their arbiter or that the selected arbiters do not agree on the head arbiter over the period each of the sides can ask the head of international judiciary tribunal to select a head arbiter from the abstaining side..."

By observing the contents of the aforementioned law it seems that the procedure of dispute settlement is a lot the same as charter. ${ }^{43}$ In the law of air transportation agreement between Iran and Philipine which is a mutual agreement has explicitly referred to the reference of differences to the arbitration in note 2 of the article 15 of this law. The aforementioned note states that: "2-in case of disagreement each of the contractors can by observing their rules and regulations in addition to sending announcements to the other sides of the contract refer the case to an arbitration committee consisted of two selected arbiters and a head arbiter. In case of referring the case to the arbitration each of the contractors should select an arbiter in sixty days after the date of receiving the announcement and the selected arbiters should select a head arbiter in sixty days time after the selection of the arbiters. In case any one of the sides of the contract does not select their arbiter or that the selected arbiters do not agree on the head arbiter over the period each of the sides can ask the head of the council of state airline international organization to select a head arbiter from the abstaining side..." Therefore it seems that the Iranian legislator intends to refer the settlement to arbitration and there is no contradiction between Iranian law and the charter. In other words it can be stated that the principle 139 can not be a serious obstacle in this respect. The question that can be asked is that does the state operation in the energy sector include the sovereignty of the state or it is an instance of undertaking? In other words given the conclusion of investment contracts in the state sector which is an instance of undertaking is part of practicing the principle 139 of the constitution is not beyond the law? It seems that the state activities in energy sector are part of exercising sovereignty because the economy of Iran is highly dependent on the energy and constitutes a large part of the national income. Therefore the state action in signing agreements can not be considered as instances of undertaking.

\subsection{Settlement of the Disputes on the Basis of Arbitration Agreement}

One of the other ways suggested by the charter to settle disputes is that the sides first follow al of the compensation ways predicted by the contract which has been agreed upon between them in advance. Therefore the tendency of the charter is towards the fact that the sides try to settle the dispute in between them without the presence of a third party or a third organ. This fact has been mentioned in parts of the article 7 and also in article 26 has been emphasized. In the legal system of Iran the agreements between the state and other governments and

\footnotetext{
${ }^{41}$ Official newspaper of Islamic Republic of Iran,N18899,2009

42 Official newspaper of Islamic Republic of Iran,N18703,2009

${ }^{43}$ - Articles 26 and 27
} 
also the foreign investors in terms of the dispute settlement has been respected. It seems that in the last two decades the number of agreements on the basis of arbitration procedure according to international arbitration rules in an unbiased place is on the rise. ${ }^{44}$ Iranian sides such as the state foundations do not have anti-international arbitration policy. In the far and near past it can be observed that the arbitration conditions are based on the non-organizational arbitration between state foundations or the private companies in arranging the bases of arbitration. In some of these cases the law of Iran has been decided as the ruling power to resolve the dispute. In two cases of them the law of Austria as the unbiased law and the law of Spain (as the law of non-Iranian law) has been selected. In another case the contract is silent concerning the ruling law. It is interesting that in a recent case between important Iranian state company and a foreign side despite the prediction in the contract for Tehran as the place of arbitration the Iranian side voluntarily accepted to change the place of arbitration to somewhere in Europe to facilitate the verification process and make it more accessible. ${ }^{45}$

In terms of the rules about the transit field such as the foreign goods transportation ratified in 997 there is no special verdict. The only case that has explicitly referred to this issue is the late part of the article 19 of the law of encouraging and supporting foreign investment ratified in 2002 which states that: "the disputes between the state and the foreign investors in terms of investment if can not resolved by negotiation they would be verified in internal tribunals unless in the mutual investment agreement another way of dispute settlement has been agreed upon. Therefore it can be observed that the principle of referring to the arbitration on the basis of the mutual arbitration agreements is accepted in legal system of Iran.

\subsection{Diplomatic and Friendly Settlement of Differences}

The other method of resolving the disputes suggested by the charter is the friendly and diplomatic way before resorting for arbitration. On the basis of this article in case the differences are not settle via this method the investor can take action in the country of investment which is approved by Iran. Use of friendly and diplomatic way of dispute settlement has not been mentioned explicitly in internal rules of Iran but it can be stated that sine the term 'negotiation' mentioned in the article 19 of the law of encouraging and supporting foreign investors is in fact a diplomatic way in terms of dispute resolution. Therefore it seems that there is no contradiction in this respect between the rules and the charter.

\section{Conclusion}

Energy charter treaty is an important multilateral international contract in the field of energy whose goal is to create freer and more competitive energy markets among the signing countries. This contract which was obligatory from 1998 has four main principle including investment, trade, transit, environment and energy efficiency. Iran has been accepted as the observer member from 2002. Since Iran is one of the largest energy producers of the world and given the extraordinary transit position of the country it is necessary to make decisions in terms of the enjoinment to a new treaty in the field of energy and the necessity of considering the benefits and costs of enjoining the treaty to enhance the national benefits.

The present study analyzed the legal regime of oil and gas transit in energy charter treaty and the law of Iran and in a comparative analysis concludes that the enjoinment of Iran to the energy charter treaty in terms of the investment is not faced with special legal obstacles that impose commitments and duties to the country. I seems that it's time that Iran makes use of its strategic position and the possession of massive oil and gas energy resources and now that there is an international treaty at international level about energy take benefit of it. It is evident that international multilateral treaties because of their expansion can not fully fulfill the goals and interests of all member countries. Every country depending on the geographic position, level of development and the political and legal regime can benefit from an international treaty.

Iran in order to benefit from the rich oil and gas resources at various fields of investment, technical knowledge and market requires the cooperation of other counties in particular the West. On the other hand the geopolitical position of Iran because of its position in between two large regions of world energy and one of the energy and goods transportation between Asia and Europe makes our presence in any international treaty by considering the aforementioned issues very essential. This special position from long ago has put Iran in all regional transit plans' framework. In addition to that by the collapse of Saddam Hussein and the created geopolitical changes in the region new facilities have created. In case the passage and transportation through the infrastructure of Iraq become possible a new channel is created that connects Iran to the Mediterranean coasts in Syria and in particular Lebanon. Use of this new path for the transportation of goods and energy can influence the East-West

\footnotetext{
44 - Miri ibid, p59

45 - Ibid,p. 115
} 
Asia-Europe paths to a large extent.

\section{References}

Clark, B. (1998). Transit and the Energy Charter Treaty: Rhetoric and Reality. Web Journal of Current Issues, 134.

Foreign goods transportation law through the territory of Islamic Republic of Iran ratified in 1997.

Haghighi, S. S. (2007). Energy Security: The External Legal Relations of the European Union with Major Oil and Gas Supplying Countries. Oxford: Har, 131.

Hashemiyan, M. (2004, Spring). summary of the workshop groups studies ECT and the political suggestions. energy international studies.

Joneidi, L. (1999). critical and comparative analysis of international trade arbitration law. Tehran, Tehran University.

Kononoplianik, A. (n.d.). The Energy Charter Treaty, A Reader's Guide, The Main Elements of the ECT (part II). Retrieved February 10, 2015, from http://www.encharter.org

Liesen, R. (1999). Transit Under The 1994 Energy Charter Treaty. Journal Of Energy and Natural Resource law, 17, 55. http://dx.doi.org/10.1080/02646811.1999.11433156

Madani, S. J. (2003). civil law judgment (7th ed.). Tehran PAYDAR.

Malekpor, M. (2007). goods transit and its importance.

Miri, Amin pasha arrangement of international trade arbitration law M.A thesis Tehran University 2002.

Mirzayi, A. (2009). arbitration law in a comparative way. Jungle publication.

Mohammadzadeye Asl, H. (2000). arbitration in the law of Iran Gognus publication.

Moslehi, A., \& Sadegi, M. (2002). substitute methods of dispute settlement tenth year N.46.

Official newspaper of Islamic Republic of Iran N.26,18899, 2009.

Official newspaper of Islamic Republic of IranN.30,18703, 2009.

Roggenkamp, M. M. (2001). Energy \& Law. University of Groningen, the Netherlands, p.114.

Seyfi, S. J. (n.d.). changes and issues and the horizon of international arbitration, Hub journal of he lawyers.

Shiravi, A. (2006). study of the sample of Ansitral law in terms of international trade reconciliation law journal tenth number.

Shiravi, A. (2008). arbitration contracts arrangement international trade arbitration law Qom high education center firs year.

Tarom Sari, M. (2005). dispute settlement in energy charter treaty international trade arbitration law summer and spring.

The executive by law of foreign goods transportation law through the territory of Islamic Republic of Iran ratified in 2000 .

\section{Copyrights}

Copyright for this article is retained by the author(s), with first publication rights granted to the journal.

This is an open-access article distributed under the terms and conditions of the Creative Commons Attribution license (http://creativecommons.org/licenses/by/3.0/). 